\title{
THE SIGNIFICANCE OF LUNG HRCT FOR THE EARLY DIAGNOSIS OF PNEUMOCONIOSIS
}

\author{
E. Petrova* \\ Preventive Medicine Department, Tokuda Medical Center, Tokuda Hospital, Sofia, Bulgaria
}

\begin{abstract}
The objective of the study was to make a comparison between the radiological perfusion of $p$ small round opacities (p) on a conventional chest radiograph (CCR) and p' opacities on a chest HRCT (CHRCT) as well as to assess the diagnostic value of HRCT in patients suspected of having nodular pneumoconiosis. 84 workers exposed to quartz, endangered by pneumoconiosis and patients with reticular and micro-nodular pneumoconiosis were studied. $A$ comparison between the mean profusion of p' small round opacities on CHRCT with the mean profusion of $p$ small round opacities on CCR was done. A multiple regression analysis was performed. The mean profusion of the p' small opacities on CHRCT was more intensive in comparison to the mean profusion of the p opacities on CCR. A statistically significant correlation between $p$ ' and $p$ opacities was found $(R=0.36337 ; P<0.001)$. CHRCT turned out to be a more sensitive image method for the detection of p small round opacities. We recommend CHRCT for the early diagnosis of reticular, reticular nodular and nodular pneumoconiosis.
\end{abstract}

Key words: CCR, HRCT, p small opacities, nodular pneumoconiosis

DOI: $10.21175 /$ RadProc.2016.24

\section{INTRODUCTION}

The striving toward the early detection of pneumoconiosis, including silicosis, forced a wide application of computed tomographic techniques during the last 20 years. According to many studies [18], chest computed tomography (CCT) and chest high resolution computed tomography (CHRCT) have a high diagnostic value in the differentiation of cases with the borderline and early fibrous and nodal image findings. The classification of Kraus et al. [5] allows the qualitative and quantitative assessment of the image findings on CHRCT in patients with pneumoconiosis.

\section{AIM}

The aim of this study is to make a comparison between the radiological perfusion of $\mathrm{p}$ small round opacities (p) on a conventional chest radiography (CCR) and p' opacities on a chest HRCT (CHRCT) as well as to assess the diagnostic value of CHRCT in patients suspected of having nodular pneumoconiosis.

\section{MATERIALS AND METHODS}

A cross sectional case control study of x-ray p small round opacities on conventional chest radiography (CCR) and p' opacities on chest HRCT (CHRCT) in patients exposed to free silicon dioxide containing dust, endangered or having reticular and reticule - micro nodular pneumoconiosis was performed. The average age of examined persons was 57.55 years, and the average quartz exposure was 15.13 years. Tomoscan - 4000 equipment was used. The examination of the lung changes on $2 \mathrm{~mm}$ thick sections with the mass index of 20mm, using software filter for target reconstruction, was performed. All lung areas from the upper thoracic aperture to the costal diaphragm area were embraced and basal sections were photographed, the first one - section on level of central pulmonary artery, and the second one - under upper thoracic aperture of the chest. The $\mathrm{x}$-ray findings on CCR were read according to the International Classification of Radiographs of Pneumoconiosis, Geneva, 1980 (ILO'80). The image findings on CHRCT were read in accordance with the Classification of high resolution computer tomography findings in pneumoconiosis, created by Kraus et al (1996). The parallel account of the radiological findings was performed by two independent radiologists by 12 degree scale for radiological profusion. The profusion of the $\mathrm{p}$ small round opacities up to $1.5 \mathrm{~mm}$ in diameter, category of $\mathrm{o} / \mathrm{O}, \mathrm{O} / 1,1 / \mathrm{O}, 1 / 1,1 / 2,2 / 1,2 / 2,2 / 3,3 / 2$, $3 / 3,3+$ on CCR were compared with the profusion of the p' small round opacities on CHRCT in the same patients. A multiple regression analysis for p' small round opacities on CHRCT toward p small opacities on CCR was done. The statistical significance was calculated. A statistical analysis with SPSS software was done.

mdepetrova@yahoo.com 


\section{RESULts}

There were 12 patients without $\mathrm{p}$ small round opacities in lung parenchyma, whereas $\mathrm{p}$ small round opacities with different profusion on CCR were found in 72 patients.

The average profusion categories (Cat.) of the p' small round opacities on CHRCT (by Kraus et al, 1996), distributed by the profusion category of $0 / 0,0 / 1,1 / 0$, $1 / 1,1 / 2,2 / 1$, and $2 / 2$ of the $p$ small round opacities on CCR (by ILO'80) are presented on Figure 1.

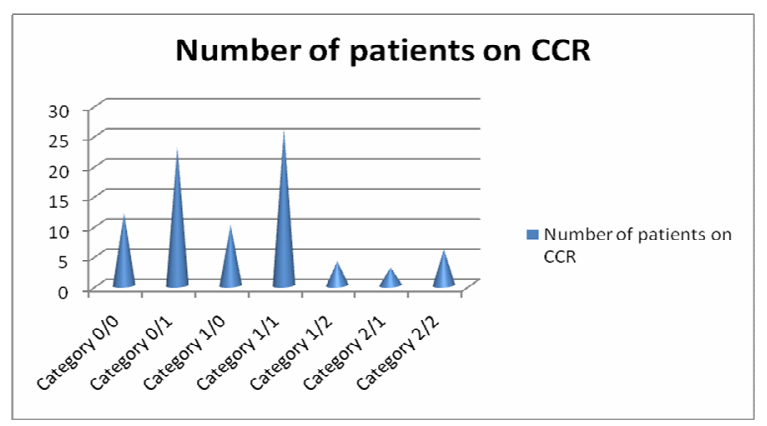

p' small round opacities on chest HRCT

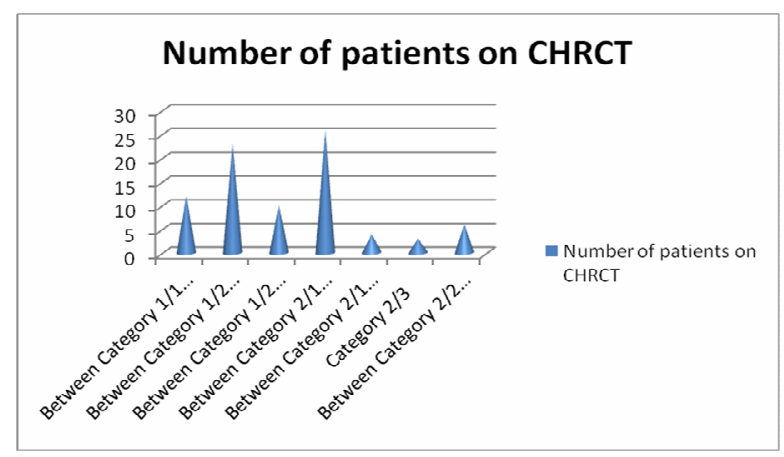

Multiple regression analysis for p' toward $\mathrm{p}$ (Correlation Coefficient = 0, 36337; Significance: $\mathrm{P}=0$, 0007 or $\mathrm{P}<0$, 001)

Figure 1. p opacities on anterior posterior chest radiography (CCR)

The average profusion of p' opacities (on CHRCT), varying between Cat. $1 / 1$ to Cat. $1 / 2$, but closer to Cat.1/2, was established n 12 (14.28\%) exposed patients of Cat. o/o (on CCR).

The average profusion of the p' opacities (on CHRCT) in 23 quartz-exposed workers with borderline reticular forms of pneumoconiosis of $\mathrm{p} \mathrm{o/1}$ (on CCR) is between Cat.1/2 and Cat. 2/1, but closer to Cat. 1/2.

Ten quartz exposed patients with the borderline reticular pneumoconiosis of p Cat. 1/o (on CCR) were with the average p' small round opacity profusion (on CHRCT) between Cat. 1/2 to Cat. 2/1, but closer to Cat. $1 / 2$.

The average profusion of the p' opacities (on CHRCT) between Cat. 2/1 and 2/2, but closer to Cat. 2/2, was established in 26 patients with the initial reticular micro nodular pneumoconiosis with $\mathrm{p}$ small round opacities of Cat. 1/1 (on PACCR).

The reticular micro nodular pneumoconiosis of $\mathrm{p}-$ Cat. $1 / 2$ (on CCR) was detected in 4 patients, with the average mean profusion of the p' opacities between Cat. 2/1 to Cat. 2/2 that was shown on CHRCT.

3 patients with $2 / 1 \mathrm{p}$ small round opacities (on CCR) presented an average profusion of p' small round opacities of Cat. 2/3 (on CHRCT).

The average profusion of p' small opacities between Cat. 2/2 and Cat. 2/3, but closer to Cat. 2/2 (on CHRCT), was detected in 6 patients with the micro nodular pneumoconiosis with $\mathrm{p}$ small round opacities of Cat. 2/2 (on CCR).

The profusion of the p' small round opacities on CHRCT was significantly more expressed in comparison to the profusion of $\mathrm{p}$ opacities on CCR.

The multiple regression analysis showed a correlation between p' and p findings on CHRCT and CCR, respectively. The Correlation coefficient $(\mathrm{R}=0$. 36337) was statistically significant $(P<0.001)$.

\section{DisCUSSION}

The patients with $\mathrm{p} \mathrm{O} / 1$ and $\mathrm{p}$ 1/o borderline pneumoconiosis (by CCR) showed a significantly higher intensive profusion of p' opacities on CHRCT, which varied between Cat. p' 1/2 and 2/1.

CHRCT revealed p' small opacities between Cat. 1/1 and $1 / 2$ but closer to $1 / 2$ in quartz-exposed workers without $\mathrm{p}$ small round opacities on CCR.

We found 2/1 to 2/2 p' small round opacities (on CHRCT) in patients with $\mathrm{p} 1 / 1$ reticular micro nodular pneumoconiosis (on CCR).

A significant correlation between p' small round opacities (on CHRCT) and p opacities on CCR (P < o.001) was found.

The CHRCT turned out to be a significantly more sensitive image method for the $\mathrm{p}$ small round opacities of $1.5 \mathrm{~mm}$ in the diameter.

\section{CONCLUSIONS}

The high sensibility of chest HRCT gave us a base to accept that this image method enables an opportunity for the early diagnosis of the initial and borderline forms of pneumoconiosis in patients exposed to quartzcontaining dust.

The image findings on CHRCT could be used as criteria for early diagnosis of different types of pneumoconiosis.

\section{REFERENCES}

1. M. Akira et al., "Early Asbestosis: Evolution with HighResolution CT1," Radiology, vol. 178, no. 2, pp. 409416, Feb. 1991

2. D.A. Gevenois, E. Pichot, F. Dargent, S. Dedeire, R.V. Weyer and P. De Vuyst, "Low Grade Coal Worker's Pneumoconiosis. Comparison of CT and Chest Radiography," Acta. Radiolog., vol. 35, no. 4, pp. 351356, July 1994

3. T.J. Harkin et al., "Differentiation of the ILO Boundary Chest Roentgenographs (o/1 to 1/o) in Asbestosis by High-Resolution Computed Tomography Scan, Alveolitis and Respiratory Impairment," J. Occup. Environ. Med., vol. 38, no. 1, pp. 46-52, Jan. 1996 
4. K.G. Hering, V. Wiebe, "Radiologic Diagnosis of Pneumoconioses," Radiologe, vol. 30, no. 12, pp. 574580, Dec. 1990

5. T. Kraus, H.J. Raithel, K.G. Hering, "Evaluation and Classification of High-Resolution Computed Tomographyc Findings in Patients with Pneumoconiosis," Int. Arch. Occup. Environ. Health, vol. 68, pp. 249-254, May 1996

6. M. Remy-Jardin, J. Remy, D. Artaud, F. Deschildre and A. Duhamel, "Diffuse Infiltrative Lung Disease: Clinical Value of Sliding-Thin-Slab Maximum Intensity Projection CT Scan in the Detection of Mild Micronodular Patterns," Radiology, vol. 200, no.2, pp. 333- 339, Aug. 1996

7. L. Olivetti et al., "Definizione anatomo-radiologica della silicosi minima interstiziale e contributo diagnostico della tomografia computerizzata con alta risolutione," Radiol. Med., vol. 85, nu. 5, pp. 600-605, Mag. 1993 (L. Olivetti et al., "Anatomo-Radiologic Definition of Minimal Interstitial Silicosis and Diagnostic Contribution of High-Resolution Computerized Tomography," Radiol. Med., vol. 85, no. 5, pp. 600-605, May 1993)

8. D. Talini et al., "Chest Radiography and High-Resolution Computed Tomography in the Evolution of Workers Exposed to Silica Dust: Relation with Function Findings," Occup. Environ. Med., vol. 52, no. 4, pp. 262267, 1995 